Check for updates

Cite this: RSC Adv., 2019, 9, 29456

\section{Formation and dissociation of synthetic hetero- double-helix complex in aqueous solutions: significant effect of water content on dynamics of structural change $\dagger$}

\author{
Tsukasa Sawato, Ryosuke Yuzawa, Higashi Kobayashi, Nozomi Saito \\ and Masahiko Yamaguchi (D) *
}

\begin{abstract}
A $1: 1$ mixture of the ethynylhelicene pseudoenantiomers $(M)$-tetramer and $(P)$-pentamer, which possess hydrophilic terminal tri(ethyleneglycol) (TEG) groups, changes their structures in the water-THF (10 $\mu \mathrm{M})$ solvent system between dissociated random-coils and an associated hetero-double-helix upon heating and cooling. A small change in water content between 30 and 33\% significantly affects the dynamics of structural changes. At $30 \%$ water content, heating to $60{ }^{\circ} \mathrm{C}$ causes rapid formation of random-coil and cooling to $10{ }^{\circ} \mathrm{C}$ causes the rapid formation of hetero-double-helix, accompanied by repeated changes in $\Delta \varepsilon$ at $369 \mathrm{~nm}$ between 0 and $-2000 \mathrm{~cm}^{-1} \mathrm{M}^{-1}$. Heating and cooling experiments at constant rates between 60 and $10{ }^{\circ} \mathrm{C}$ resulted in sigmoidal curves in $\Delta \varepsilon$ /temperature profiles, which indicate rapid structural changes. Different phenomena occurred at $33 \%$ water content. Heating to $60^{\circ} \mathrm{C}$ and cooling to $0{ }^{\circ} \mathrm{C}$ initially induced changes in $\Delta \varepsilon$ between 0 and $-2000 \mathrm{~cm}^{-1} \mathrm{M}^{-1}$, and repeated cycles gradually reduced the range between 0 and $-500 \mathrm{~cm}^{-1} \mathrm{M}^{-1}$. Heating and cooling experiments at constant rates between 60 and $10{ }^{\circ} \mathrm{C}$ caused small changes in $\Delta \varepsilon$, and repeated cycles at $10^{\circ} \mathrm{C}$ gradually increased $\Delta \varepsilon$ to $-500 \mathrm{~cm}^{-1} \mathrm{M}^{-1}$. These phenomena involved rapid changes in molecular structure and slow structural changes in the water-THF solvent system. The sharp switching of the dynamics of structural changes at water content between 30 and 33\% indicated discontinuous structural changes in the hydration of TEG and/or in water clusters in the vicinity of oligomer molecules.
\end{abstract}

Received 5th August 2019

Accepted 8th September 2019

DOI: $10.1039 / c 9 r a 06073 a$

rsc.li/rsc-advances tri(ethyleneglycol) (TEG) groups formed homo-double-helix in mixed solutions of water and organic solvents. ${ }^{9,10}$ Association and dissociation showed an inverse thermoresponse, in which heating induced association and cooling induced dissociation. Inverse thermoresponses I and II were observed depending on the organic cosolvents used. These unusual thermoresponses were ascribed to the hydration/dehydration of the TEG groups and/or structural changes of water clusters in the vicinity of the oligomer molecules.

It was also found that mixtures of the ethynylhelicene pseudoenantiomers $(M)$-oligomer and $(P)$-oligomer with different helicene numbers formed hetero-double-helix in organic solvents. ${ }^{10-12}$ In this study, a water-soluble heterodouble-helix was developed employing a mixture of pseudoenantiomers ethynylhelicene $(M)$-tetramer $(M)$-1 and $(P)$-pentamer $(P)-2$, which possess terminal hydrophilic TEG groups (Fig. 1b).

The $(M)-1 /(P)-2$ mixture formed a hetero-double-helix in water-THF solvent system, which switched the dynamics of structural changes with the change in water content from 30 to $33 \%$ (Fig. 1a). At $30 \%$ water content, repeated heating to $60{ }^{\circ} \mathrm{C}$ and cooling to $10{ }^{\circ} \mathrm{C}$ changed $\Delta \varepsilon$ at $369 \mathrm{~nm}$ between 0 and
Department of Organic Chemistry, Graduate School of Pharmaceutical Sciences, Tohoku University, Aoba, Sendai 980-8578, Japan. E-mail: yama@m.tohoku.ac.jp; Fax: +81-22-795-6811

$\dagger$ Electronic supplementary information (ESI) available: Full experimental details including general methods, CD, UV-vis, DLS. See DOI: 10.1039/c9ra06073a 
(a)
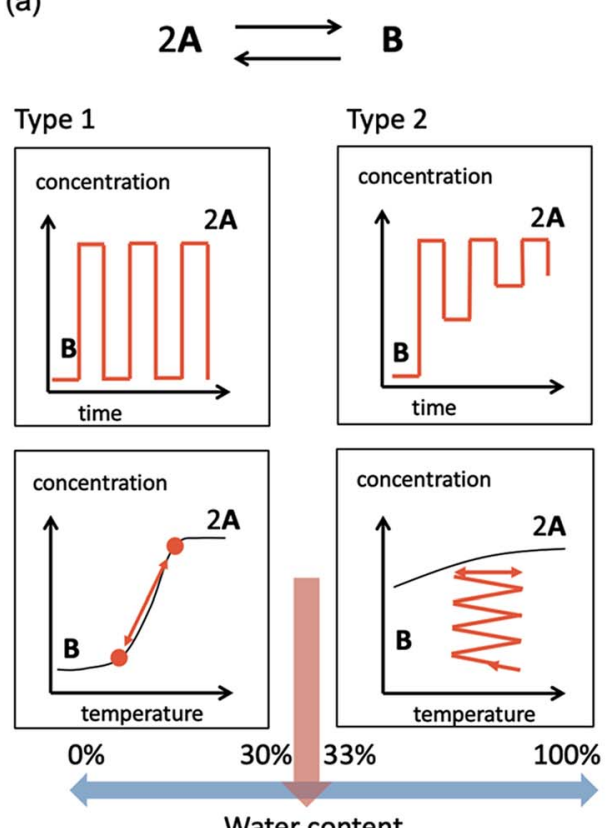

(b)

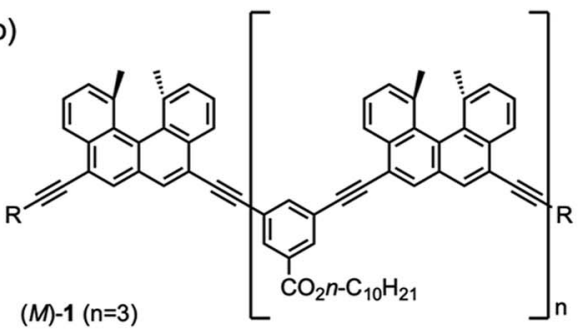

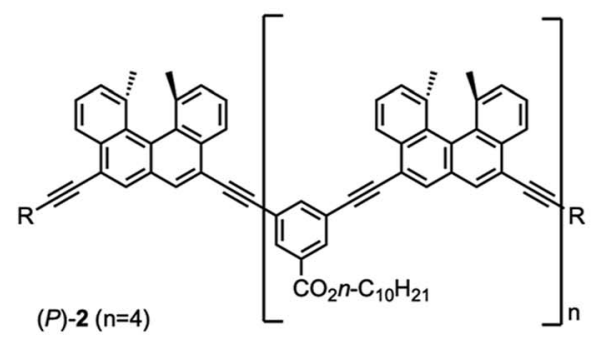

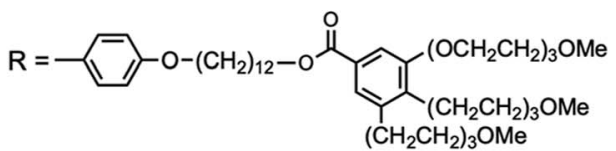

Fig. 1 (a) Schematic presentation of dynamics of structural changes between hetero-double-helix B and random-coils 2A in water-THF solvent system, in which the changes in the water content from 30\% to 33\% significantly affected the dynamics, termed type I and II, respectively, as mentioned later in this paper. Red lines indicate the experimental structural change dynamics, and black lines indicate the equilibrium curves. (b) Chemical structures of $(M)-1$ and $(P)-2$.

$-2000 \mathrm{~cm}^{-1} \mathrm{M}^{-1}$, which rapidly occurred in response to temperature changes. Constant-rate heating and cooling resulted in sigmoidal curves. At $33 \%$ water content, heating to $60{ }^{\circ} \mathrm{C}$ and cooling to $10{ }^{\circ} \mathrm{C}$ initially changed $\Delta \varepsilon$ between -2000 and
$0 \mathrm{~cm}^{-1} \mathrm{M}^{-1}$, and repeated heating/cooling cycles gradually reduced the range between -500 and $0 \mathrm{~cm}^{-1} \mathrm{M}^{-1}$. Heating and cooling at a constant rate resulted in smaller changes in $\Delta \varepsilon$. These phenomena suggest the involvement of rapid changes in
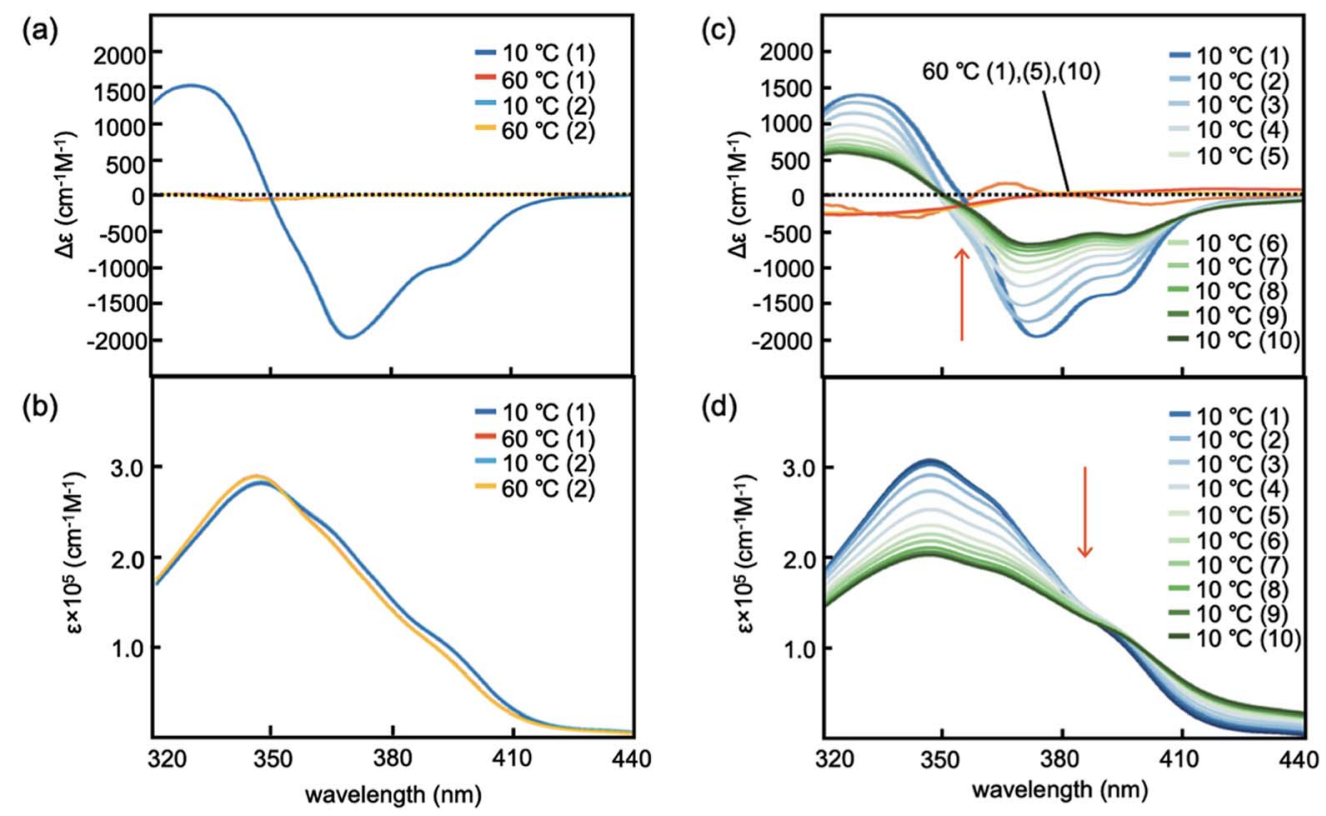

Fig. 2 (a) CD and (b) UV-vis spectra of $(M)-1 /(P)-2(1: 1)$ in 30\% water-THF $(10 \mu M)$ at 60 and $10^{\circ} \mathrm{C}$. (c) CD and (d) UV-vis spectra of $(M)-1 /(P)-2$ $(1: 1)$ in $33 \%$ water-THF $(10 \mu \mathrm{M})$ at 60 and $10{ }^{\circ} \mathrm{C}$. The numbers of heating/cooling cycles is shown in parentheses. See Fig. S8a† for details of the spectra in (c) and (d). 
molecular structure and slow structural changes in the waterTHF solvent system. The sharp switching of dynamics of structural changes caused by the small change in water content indicates a discontinuous change in the hydration/dehydration of TEG groups and/or water clusters in the vicinity of the oligomers.

\section{Results and discussion}

\section{Experiments in water-THF solvent system with $30 \%$ water}

Hetero-double-helix formation by the $(M)-1 /(P)-2$ mixture was examined using $10 \mu \mathrm{M}$ in water-THF solvent system with $30 \%$ water, which is hereafter referred as $30 \%$ water-THF in this paper. The solution was prepared by mixing two solutions of $(M)-1$ and $(P)-2$ in 30\% water-THF at 1:1 ratio. Heating the resulting solution to $60^{\circ} \mathrm{C}$ produced dissociated random-coil $2 \mathrm{~A}$ exhibiting a weak Cotton effect, as shown by circular dichroism (CD) spectroscopy (Fig. 2a and $\mathrm{S} 1 \dagger$ ). Cooling the solution to $10{ }^{\circ} \mathrm{C}$ showed a strong negative Cotton effect at $369 \mathrm{~nm}$ with $\Delta \varepsilon$ reaching $-2000 \mathrm{~cm}^{-1} \mathrm{M}^{-1}$, and the Cotton effect disappeared upon heating the solution to $60{ }^{\circ} \mathrm{C}$. UV-vis spectra showed slightly reduced intensity upon cooling to $10{ }^{\circ} \mathrm{C}$ (Fig. $2 \mathrm{~b}$ and $\mathrm{S} 1 \dagger)$. These results were consistent with the structural changes between $2 \mathbf{A}$ and hetero-double-helix $\mathbf{B} .^{9}$ The experiment was also conducted using a $100 \mu \mathrm{M}$ solution, and CD spectra obtained at $10{ }^{\circ} \mathrm{C}$ were very similar to those of the $10 \mu \mathrm{M}$ solution (Fig. S7 $\dagger$ ), which indicated that the $\mathrm{CD}$ spectrum with $\Delta \varepsilon$ reaching $-1500 \mathrm{~cm}^{-1} \mathrm{M}^{-1}$ showed the equilibrium shifted to $\mathbf{B}$ and essentially contained no $2 \mathbf{A}$. Hetero-double-helix formation by the $(M)-1 /(P)-2$ mixture in water-THF solvent system occurred at $\mu \mathrm{M}$-order concentrations that was much more extensive than that in organic solvents at mM-order concentrations. ${ }^{\mathbf{1 1 - 1 3}}$ Dynamic light scattering (DLS) analysis (30\% water-THF, 10 $\mu \mathrm{M})$ at 10 and $60{ }^{\circ} \mathrm{C}$ showed the formation of particles with average diameters smaller than $10 \mathrm{~nm}$ (Fig. S2 $\dagger$ ). Consequently, no Tyndall effect was observed. Therefore, the thermoresponse of the $(M)-\mathbf{1} /(P)-2$ mixture observed by CD spectroscopy is derived from molecules dispersed in solution that do not form larger aggregates.

Experiments of repeated and periodic heating to $60{ }^{\circ} \mathrm{C}$ and cooling to $10{ }^{\circ} \mathrm{C}$ were conducted, and structural changes were monitored on the basis of $\Delta \varepsilon$. Sharp structural changes appeared between 0 and $-2000 \mathrm{~cm}^{-1} \mathrm{M}^{-1}$ as shown by the rectangular shapes of $\Delta \varepsilon$ /time profiles (Fig. $3 \mathrm{a}$ and $\mathrm{S} 6 \mathrm{~b} \dagger$ ), which indicated rapid structural changes between molecules of $2 \mathbf{A}$ and B. Other experiments with nonperiodic temperature changes also yielded rectangular shapes of profiles (Fig. S6a $\dagger$ ).

Heating and cooling experiments at constant rate were conducted between 60 and $10{ }^{\circ} \mathrm{C}$ at a constant rate of $1^{\circ} \mathrm{C} \mathrm{min}{ }^{-1}$ in $30 \%$ water-THF (Fig. $4 \mathrm{a}$ and S16 $\dagger$ ). $\Delta \varepsilon$ at $375 \mathrm{~nm}$ decreased from $0 \mathrm{~cm}^{-1} \mathrm{M}^{-1}$ at $60{ }^{\circ} \mathrm{C}$, and reached $-2000 \mathrm{~cm}^{-1} \mathrm{M}^{-1}$ at $10{ }^{\circ} \mathrm{C}$. Sigmoidal curves were obtained during heating and cooling with a small thermal hysteresis, which is consistent with the observed rapid structural changes between molecules of $2 \mathbf{A}$ and $\mathbf{B}$ (Fig. 3a). These phenomena in $30 \%$ water-THF are termed type- 1 behavior in this paper.

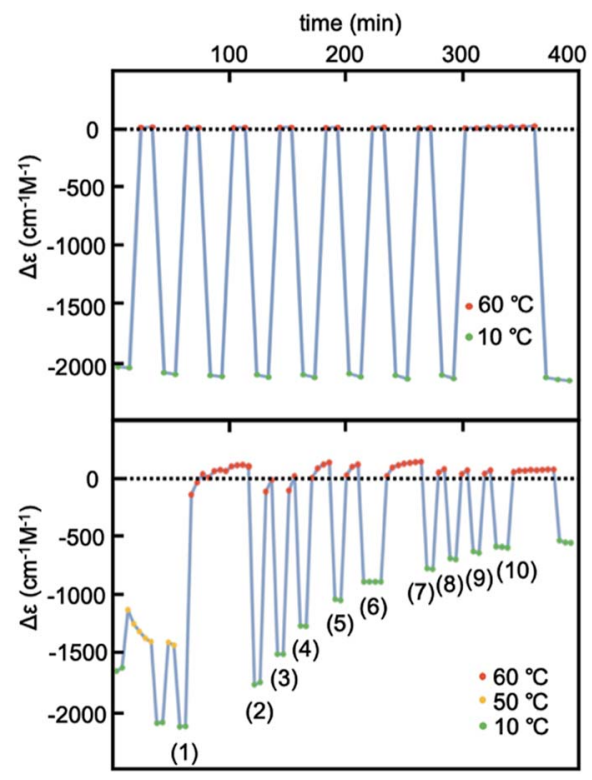

Fig. 3 Experiments of repeated heating and cooling of $(M)-1 /(P)-2$ (1: 1) between 60 and $10{ }^{\circ} \mathrm{C}$ for $\Delta \varepsilon$ at $369 \mathrm{~nm}$ in (a) $30 \%$ water-THF (10 $\mu \mathrm{M})$ and for $\Delta \varepsilon$ at $376 \mathrm{~nm}$ in (b) $33 \%$ water-THF (10 $\mu \mathrm{M})$.

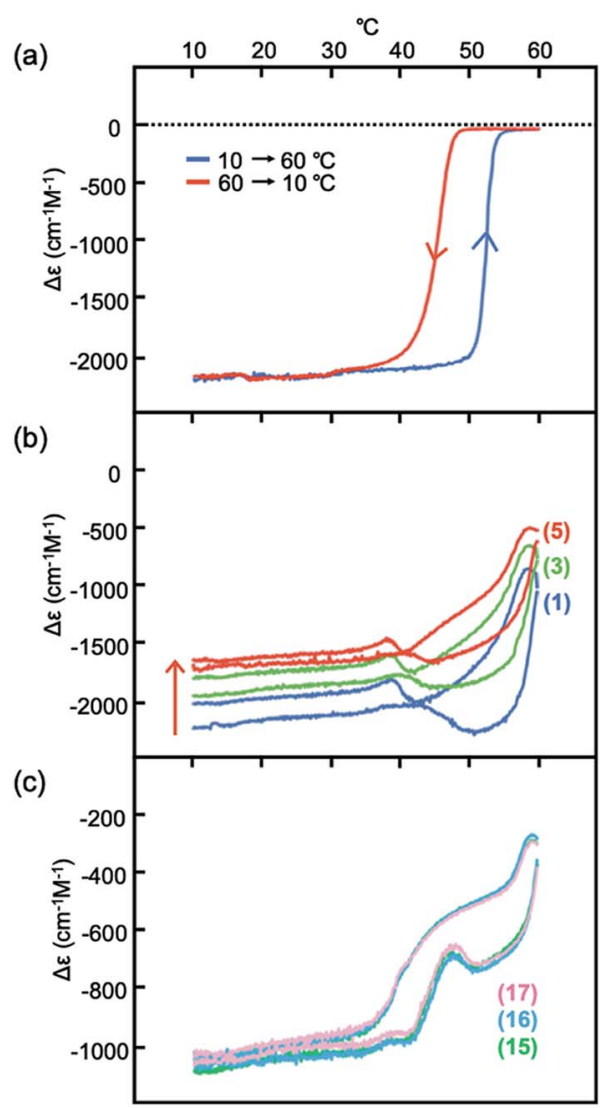

Fig. $4 \Delta \varepsilon(375 \mathrm{~nm}) /$ temperature profiles from experiments of heating and cooling of $(M)-1 /(P)-2(1: 1)$ at a constant rate of $1{ }^{\circ} \mathrm{C} \mathrm{min}{ }^{-1}$ between 10 and $60{ }^{\circ} \mathrm{C}$, shown by (a) in $30 \%$ water-THF $(10 \mu \mathrm{M})$; (b) in $33 \%$ water-THF $(10 \mu \mathrm{M})$ starting from $-2000 \mathrm{~cm}^{-1} \mathrm{M}^{-1}$; (c) enlarged view of (b). The number of heating/cooling cycles is shown in parentheses in (b) and (c). See Fig. S17 $\uparrow$ for details. 


\section{Experiments in water-THF solvent system with $33 \%$ water}

When water content was increased to $33 \%$, different phenomena were observed. A $(M)-\mathbf{1} /(P)-2$ mixture in $33 \%$ waterTHF $(10 \mu \mathrm{M})$ was prepared by mixing two solutions of $(M)-\mathbf{1}$ and $(P)-2$ in $33 \%$ water-THF $(10 \mu \mathrm{M})$ at $1: 1$ ratio at room temperature. The resulting mixture was heated to $50{ }^{\circ} \mathrm{C}$ and cooled to $10{ }^{\circ} \mathrm{C}$, during which a strong negative Cotton effect was observed at $376 \mathrm{~nm}$ with $\Delta \varepsilon$ reaching $-2100 \mathrm{~cm}^{-1} \mathrm{M}^{-1}$ (Fig. S8a $\dagger$ ). When heated to $50{ }^{\circ} \mathrm{C}, \Delta \varepsilon$ increased to $-1500 \mathrm{~cm}^{-1}$ $\mathrm{M}^{-1}$. Then, the solution was heated to $60^{\circ} \mathrm{C}$ and cooled to $10^{\circ} \mathrm{C}$, during which $\Delta \varepsilon$ changed between 0 and $-1700 \mathrm{~cm}^{-1} \mathrm{M}^{-1}$. Repeated heating/cooling cycles gradually decreased the $\Delta \varepsilon$ range, and $\Delta \varepsilon$ at $10{ }^{\circ} \mathrm{C}$ reached $-500 \mathrm{~cm}^{-1} \mathrm{M}^{-1}$ after 10 cycles (Fig. 2c). UV-vis spectra also showed changes in intensity as a result of repeated heating to $60{ }^{\circ} \mathrm{C}$ and cooling to $10{ }^{\circ} \mathrm{C}$ (Fig. 2d). The structure of the $(M)-1 /(P)-2$ mixture in 33\% waterTHF $(10 \mu \mathrm{M})$ was examined by dynamic light scattering (DLS) analysis at 10,50 , and $60{ }^{\circ} \mathrm{C}$, which showed the formation of particles smaller than $10 \mathrm{~nm}$ (Fig. S3†). No Tyndall effect was observed during the process, indicating that the structural changes were molecular events in solution.

Experiments of repeated heating and cooling between 50 and $10{ }^{\circ} \mathrm{C}$ showed $\Delta \varepsilon(376 \mathrm{~nm}) /$ time profiles indicating $\Delta \varepsilon$ changes between -1500 and $-2200 \mathrm{~cm}^{-1} \mathrm{M}^{-1}$ (Fig. 3b and S8a $\dagger$ ). The experiments between 60 and $10{ }^{\circ} \mathrm{C}$ showed $\Delta \varepsilon$ changes between 0 and $-1700 \mathrm{~cm}^{-1} \mathrm{M}^{-1}$, which on repeated heating/cooling cycles between 60 and $10{ }^{\circ} \mathrm{C}$ gradually decreased the $\Delta \varepsilon$ range between 0 and $-500 \mathrm{~cm}^{-1} \mathrm{M}^{-1}$ after 10 cycles, and reached a steady state. Rectangular shapes of $\Delta \varepsilon /$ time profiles with slight deviations showed that rapid structural changes occurred between molecules of $2 \mathbf{A}$ and $\mathbf{B}$. The gradual decrease in the $\Delta \varepsilon$ range with repeated heating/cooling cycles suggests a structural change of the water-THF solvent system.

Constant-rate heating and cooling experiments in $33 \%$ water-THF also exhibited dynamics of structural changes different from those in 30\% water-THF. A $(M)-\mathbf{1} /(P)-2$ mixture in $33 \%$ water-THF $(10 \mu \mathrm{M})$ with $\Delta \varepsilon$ reaching $-2000 \mathrm{~cm}^{-1} \mathrm{M}^{-1}$ was obtained at $10{ }^{\circ} \mathrm{C}$; the solution was then heated to $60{ }^{\circ} \mathrm{C}$ and cooled to $10^{\circ} \mathrm{C}$ at a rate of $1{ }^{\circ} \mathrm{C} \min ^{-1}$ (Fig. $4 \mathrm{~b}$ and $\mathrm{S} 17 \dagger$ ). Upon heating, $\Delta \varepsilon$ not change up to $45{ }^{\circ} \mathrm{C}$, and then increased to $-1000 \mathrm{~cm}^{-1} \mathrm{M}^{-1}$ at $60{ }^{\circ} \mathrm{C}$. Upon cooling, $\Delta \varepsilon$ decreased to
$-2000 \mathrm{~cm}^{-1} \mathrm{M}^{-1}$ at $40{ }^{\circ} \mathrm{C}$, and remained constant until $10{ }^{\circ} \mathrm{C}$. The small changes in $\Delta \varepsilon$ in $33 \%$ water-THF were compared with large changes in 30\% water-THF (Fig. 4a). Repeated heating and cooling experiments showed small changes for every cycle, and $\Delta \varepsilon$ at $10{ }^{\circ} \mathrm{C}$ gradually increased, reaching $-1600 \mathrm{~cm}^{-1} \mathrm{M}^{-1}$ after 5 cycles and $-1000 \mathrm{~cm}^{-1} \mathrm{M}^{-1}$ after 17 cycles (Fig. $4 \mathrm{c}$ ). A small thermal hysteresis was observed for every cycle between 40 and $60{ }^{\circ} \mathrm{C}$. The results of the constant-rate heating and cooling experiments in $33 \%$ water-THF indicated slow responses of $\Delta \varepsilon$ to temperature changes. The phenomena in $33 \%$ water-THF are referred to as type- 2 behavior in the following discussions. Sharp switching in dynamics of structural changes appeared in the $(M)-\mathbf{1} /(P)-2$ mixture for small changes in water content from $30 \%$ for type-1 behavior to $33 \%$ for type-2 behavior.

The effect of substrate concentration was examined in $33 \%$ water-THF. The structural changes between -1000 and $0 \mathrm{~cm}^{-1}$ $\mathrm{M}^{-1}$ appeared at 5 and $7.5 \mu \mathrm{M}$ as well as $10 \mu \mathrm{M}$, which are the type-2 behavior (Fig. S9 and S10 $\dagger$ ).

Experiments were conducted in water-THF solvent system with different water contents. In $25 \%$ water-THF, heating to $60{ }^{\circ} \mathrm{C}$ and cooling to $10{ }^{\circ} \mathrm{C}$ showed structural changes between $\Delta \varepsilon 0$ and $-2300 \mathrm{~cm}^{-1} \mathrm{M}^{-1}$, which is the type- 1 behavior (Fig. 55 and $\mathrm{S} 15 \dagger$ ). In $40 \%$ water-THF, heating to $50{ }^{\circ} \mathrm{C}$ and cooling to $10{ }^{\circ} \mathrm{C}$ showed structural changes between $\Delta \varepsilon-1200$ and $-1700 \mathrm{~cm}^{-1} \mathrm{M}^{-1}$, which changed between -200 and $-1200 \mathrm{~cm}^{-1} \mathrm{M}^{-1}$ upon heating to $60{ }^{\circ} \mathrm{C}$ and cooling to $10{ }^{\circ} \mathrm{C}$; these changes are the type- 2 behavior (Fig. S11†). Constant-rate temperature change experiments showed similar $\Delta \varepsilon /$ temperature profiles of $40 \%$ water-THF to those of $33 \%$ water-THF (Fig. S18 $\dagger$ ). An important role of water in the type- 1 and type-2 behaviors was confirmed by experiments in THF without water, in which dissociated $\mathbf{2 A}$ persisted without formation of $\mathbf{B}$ upon heating and cooling (Fig. S4†). These results indicate a sharp switching in dynamics of the structural changes of the $(M)-\mathbf{1} /(P)-2$ mixture at water contents between 30 and $33 \%$ owing to the type- 1 and -2 behaviors.

\section{Experiments involving changes in water content}

In the above experiments, the $(M)-\mathbf{1} /(P)-2$ mixture in $30 \%$ waterTHF $(10 \mu \mathrm{M})$ was prepared by mixing two solutions of $(M)-\mathbf{1}$ and (a)

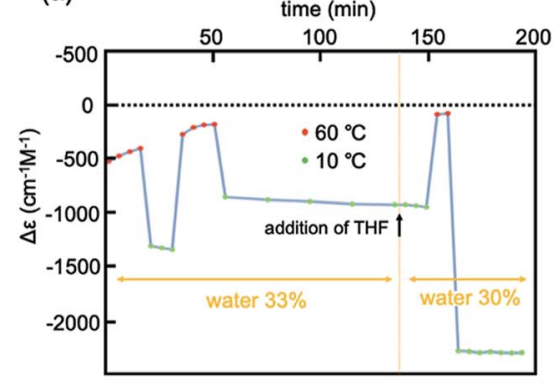

(b)

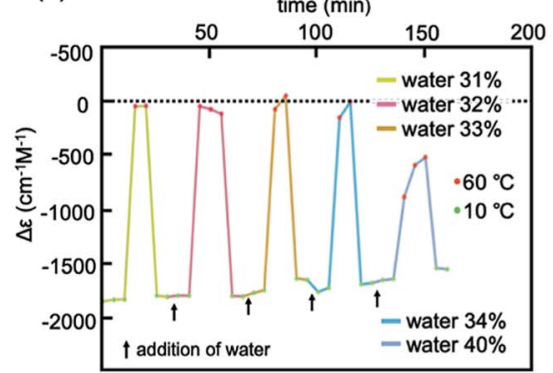

(c)

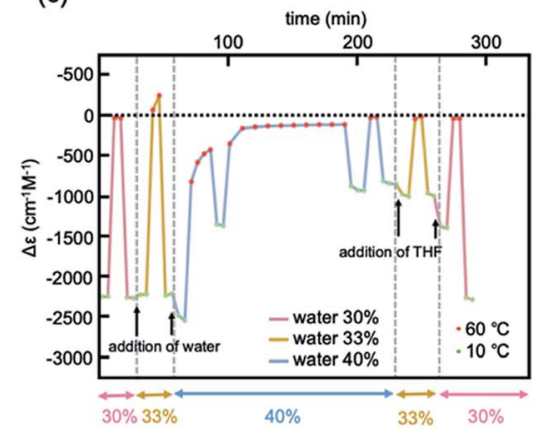

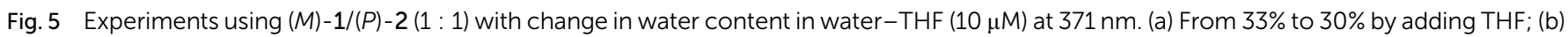
from $30 \%$ to $31,32,33$, and $34 \%$ by adding water; (c) from $30 \%$ to $33 \%$, and $40 \%$ by adding water, and then to $33 \%$ by adding THF. 
$(P)-2$ in $30 \%$ water-THF. Another procedure was examined, in which the water content was changed from $33 \%$ to $30 \%$ in a single vessel by adding THF to $33 \%$ water-THF. A $(M)-1 /(P)-2$ mixture in $33 \%$ water-THF $(10 \mu \mathrm{M})$ was prepared by mixing two solutions of $(M)-1$ and $(P)-2$ in 33\% water-THF, and the resulting solution showed structural changes between -300 and $-1300 \mathrm{~cm}^{-1} \mathrm{M}^{-1}$ upon heating to $60{ }^{\circ} \mathrm{C}$ and cooling to $10{ }^{\circ} \mathrm{C}$, which is the type- 2 behavior (Fig. $5 \mathrm{a}$ and S12 $\dagger$ ). THF was added to prepare a $30 \%$ water-THF solution, and the resulting solution showed structural changes between -2500 and $0 \mathrm{~cm}^{-1}$ $\mathbf{M}^{-1}$, which is the type-1 behavior. Rectangular shapes of structural changes in $\Delta \varepsilon$ /time profiles are consistent with rapid structural changes between molecules of $\mathbf{2 A}$ and $\mathbf{B}$. These results confirmed the sharp switching of dynamics of the structural changes of the $(M)-\mathbf{1} /(P)-2$ mixture caused by changing the water content from 33 to $30 \%$.

A reverse experiment, in which $30 \%$ water-THF $(10 \mu \mathrm{M})$ was changed to $33 \%$ water-THF in a single vessel by adding water, showed different phenomena. A $(M)-\mathbf{1} /(P)-2$ mixture in $30 \%$ water-THF was prepared by mixing two solutions of $(M)-\mathbf{1}$ and $(P)-2$ in $30 \%$ water-THF; this showed structural changes between -1800 and $0 \mathrm{~cm}^{-1} \mathrm{M}^{-1}$ upon cooling to $10{ }^{\circ} \mathrm{C}$ and heating to $60{ }^{\circ} \mathrm{C}$, as the type- 1 behavior (Fig. $5 \mathrm{~b}$ and $\mathrm{S} 13 \dagger$ ). Water was added to obtain $31 \%$ water-THF solution, which also showed structural changes between -1800 and $0 \mathrm{~cm}^{-1} \mathrm{M}^{-1}$ (type-1 behavior). The type-1 behavior also appeared in 32, 33, and $34 \%$ water-THF upon addition of portions of water. Simply increasing of the water content from $30 \%$ to $33 \%$ did not result in a switch from the type- 1 to type- 2 behavior. Rectangular shapes associated with structural changes appearing in $\Delta \varepsilon /$ time profiles are consistent with rapid structural changes of molecules of $(M)-1$ and $(P)-2$.

It was observed that the type- 2 behavior appeared as a result of addition of THF to $40 \%$ water-THF solution (Fig. $5 \mathrm{c}$ and $\mathrm{S} 14 \dagger)$. Water was added to $(M)-\mathbf{1} /(P)-2$ mixture in $30 \%$ waterTHF to prepare $40 \%$ water-THF, which showed structural changes between -1000 and $0 \mathrm{~cm}^{-1} \mathrm{M}^{-1}$ (type- 2 behavior). THF was added to prepare $33 \%$ water-THF, and the structural changes between -1000 and $0 \mathrm{~cm}^{-1} \mathrm{M}^{-1}$ was observed, which are the type- 2 behavior. To switch from the type- 1 to type- 2 behavior, it is essential to employ complex procedures involving the addition of water to $30 \%$ water-THF to prepare $40 \%$ water-THF and the addition of THF to prepare $33 \%$ waterTHF. The phenomenon is consistent with slow structural changes in the water-THF solvent system as a result of changing the water content from 30 to $33 \%$.

\section{Mechanistic model}

A mechanism underlying the different dynamics of structural changes between $2 \mathbf{A}$ and $\mathbf{B}$ in 30 and 33\% water-THF defined as the type- 1 and type- 2 behaviors, respectively, is proposed, in which the dynamics of structural changes between molecules of $\mathbf{2 A}$ and $\mathbf{B}$ and the water-THF solvent system were separately considered (Fig. 6). Structural changes of molecules of $2 \mathbf{A}$ and $\mathbf{B}$ are rapid both in $30 \%$ and $33 \%$ water-THF solutions (Fig. 6b, black arrows), which are shown by rectangular shapes and small thermal hysteresis (Fig. 3 and 4). The dynamics of slow structural changes of $33 \%$ water-THF was ascribed to the slow structural changes of the solvent system. In $30 \%$ water-THF, the equilibrium state at $10^{\circ} \mathrm{C}$ is close to $\Delta \varepsilon-2000 \mathrm{~cm}^{-1} \mathrm{M}^{-1}$ and at $0 \mathrm{~cm}^{-1} \mathrm{M}^{-1}$ at $60{ }^{\circ} \mathrm{C}$, and the structural changes are fast (Fig. 6a). In $33 \%$ water-THF, the $\Delta \varepsilon$ range gradually narrowed

(a)

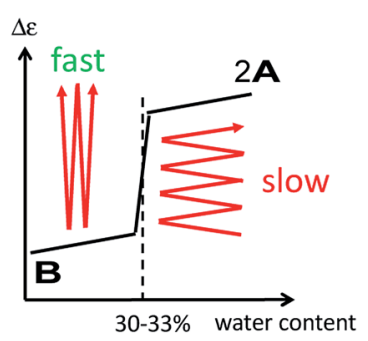

(b) $30 \%$ water content
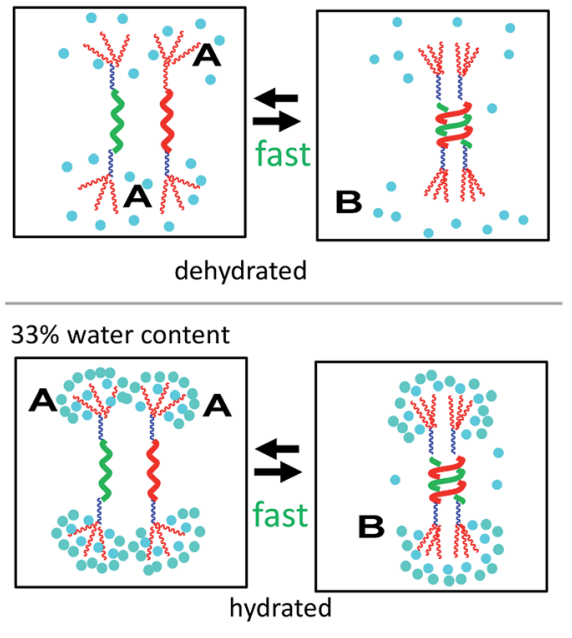

slow

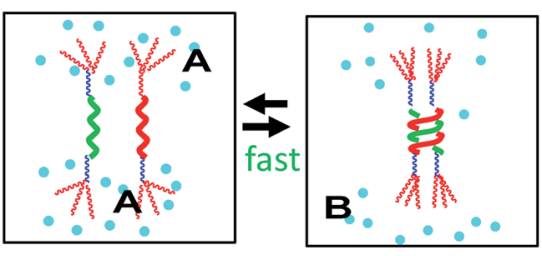

dehydrated

Fig. 6 (a) Mechanistic model of dynamics in the structural changes shown by $\Delta \varepsilon /$ water content profiles in $30 \%$ water-THF (type-1 behavior) and $33 \%$ water-THF (type-2 behavior). Red arrows indicate structural changes between random-coil $2 \mathrm{~A}$ and hetero-double-helix B. Black lines show the equilibrium state at $10{ }^{\circ} \mathrm{C}$, which switches between 30 and 33\% water-THF. (b) Mechanistic model of type-1 and type-2 behaviors. In the type-1 behavior, rapid molecular structural changes between molecules of $2 \mathrm{~A}$ and $\mathrm{B}$ occur upon heating and cooling, which are shown by black arrows. In the type- 2 behavior, rapid structural changes between molecules of $2 \mathrm{~A}$ and $\mathrm{B}$ occur upon heating and cooling, and slow structural changes of the water-THF solvent system occur. Repeated heating and cooling slowly changes the structure of the solvent system, which is shown by bold dark red arrows. Blue circles indicate water molecules, which undergo slow changes in their hydrated/dehydrated state and/or water cluster structure. 
after repeated heating/cooling cycles from 0 and $-2000 \mathrm{~cm}^{-1}$ $\mathrm{M}^{-1}$ to 0 and $-500 \mathrm{~cm}^{-1} \mathrm{M}^{-1}$, which can be ascribed to the slow structural changes of the $33 \%$ water-THF (Fig. 6b). Repeated heating and cooling is required to approach the equilibrium state of in the $33 \%$ water-THF. The equilibrium state at $10{ }^{\circ} \mathrm{C}$ may be close to $-500 \mathrm{~cm}^{-1} \mathrm{M}^{-1}$. Thus, structural changes of molecules of $\mathbf{2 A}$ and $\mathbf{B}$ are rapid in 30 and $33 \%$ water-THF, and structural changes of the $33 \%$ water-THF solvent system are slow. Such sharp switching of structural changes of $(M)-\mathbf{1} /(P)-2$ mixtures can be used to sense subtle environmental changes.

The change in the structure of the solvent system can be described by the changes in the hydrated/dehydrated state of the TEG groups and/or by the changes in the structure of water clusters. In water-THF solvent system with water content below $30 \%$, hetero-double-helix formation is rapid in response to temperature changes, because the TEG groups are less hydrated. In water-THF solvent system with water content above $33 \%$, interconversion between molecules of $\mathbf{2 A}$ and $\mathbf{B}$ is rapid, and the hydration-dehydration of TEG groups becomes slow. Alternatively, the structure of water clusters in the vicinity of the molecules of $\mathbf{B}$ changes depending on the water content, which slowly responds to temperature changes.

\section{Conclusions}

The nature of homo- and hetero-double-helix derived from TEGcontaining ethynylhelicene oligomers was compared in waterTHF solvent system at $10 \mu \mathrm{M}$. A notable difference is the ordinary thermoresponse of hetero-double-helix as observed in this study and the inverse thermoresponses of homo-double-helix as described previously. ${ }^{9,10}$ It is considered that this difference may be derived from the hydration/dehydration structures of the TEG groups and/or water cluster structures in the vicinity of oligomer molecules. The effect of water content on structural changes of homo- and hetero-double-helix complexes in this study is also notable. Between 30 and $33 \%$ water contents, the interconversion between $\mathbf{2 A}$ and $\mathbf{B}$ showed significant switching in dynamics of the structural changes, as described by the type1 and type-2 behaviors. It was previously observed that a homodouble-helix formed by $(P)-1$ showed significant switching in dynamics of structural changes at water contents below and above $30 \%$ in water-THF solvent system, which switched from ordinary thermoresponse to inverse thermoresponse II. ${ }^{10}$ Thus, the nature of structural changes derived from hydration/ dehydration of TEG groups and/or water clusters in the vicinity of the oligomer molecules appears to change at water contents of approximately $30 \%$.

Mixed solvent systems of water and THF have attracted interest, and the dependence of their thermodynamic properties as a function of water content has been studied. Changes in the properties of water-THF solvent systems appeared at $70 \%$ water content, as shown by viscosity, X-ray scattering, molecular aggregation, and fluorescence analyses. ${ }^{14-19}$ In contrast, a change at $30 \%$ water content was observed in this study and in the inverse thermoresponse $\mathrm{II},{ }^{10}$ which can partly be due to the nature of interactions between TEG groups and water clusters.
To summarize, a $1: 1$ mixture of the ethynylhelicene pseudoenantiomers, $(M)$-tetramer and $(P)$-pentamer, both of which possess hydrophilic terminal TEG groups, formed heterodouble-helix and random-coils in water-THF solvent system at $10 \mu \mathrm{M}$. A small change in water content from 30 to $33 \%$ significantly affected dynamics of the structural changes. In $30 \%$ water-THF, heating to $60{ }^{\circ} \mathrm{C}$ caused the dissociation of hetero-double-helix to random-coils, and cooling to $10{ }^{\circ} \mathrm{C}$ caused the formation of hetero-double-helix, which rapidly and repeatedly changed $\Delta \varepsilon$ between 0 and $-2000 \mathrm{~cm}^{-1} \mathrm{M}^{-1}$. Constant-rate heating and cooling experiment showed rapid changes in $\Delta \varepsilon$. In $33 \%$ water-THF, heating to $60^{\circ} \mathrm{C}$ and cooling to $10^{\circ} \mathrm{C}$ showed changes in $\Delta \varepsilon$ between 0 and $-2000 \mathrm{~cm}^{-1} \mathrm{M}^{-1}$, and repeated heating and cooling experiments gradually widened the $\Delta \varepsilon$ range to 0 and $-500 \mathrm{~cm}^{-1} \mathrm{M}^{-1}$. Constant-rate heating and cooling experiments showed small changes in $\Delta \varepsilon$, and $\Delta \varepsilon$ at $10{ }^{\circ} \mathrm{C}$ gradually increased. The dynamics in the structural changes indicated slow changes of the water-THF solvent system upon heating and cooling. Sharp switching of reaction mechanism between 30 and 33\% water contents suggests discontinuous structural changes in TEG hydration/ dehydration and/or water clusters in the vicinity of the oligomers in the water-THF solvent system. Water is a complex molecular system, ${ }^{20}$ the structure of which sensitively and significantly affects molecules depending on the structures of solutes and the water content in mixed solvent systems.

\section{Conflicts of interest}

There are no conflicts to declare.

\section{Acknowledgements}

This work was financially supported by Grants-in-Aid for Scientific Research (No. 17H03050 and 17H08203) from the Japan Society for the Promotion of Science (JSPS). H. K. thanks the JSPS for Research Fellowship for Young Scientists (No. 17J02496).

\section{Notes and references}

1 D. D Voet and J. G. Voet, Biochemistry, Wiley, New Jersey, 4th edn, 2011.

2 H. Lodish, A. Berk, C. A. Kaiser, M. Krieger, M. P. Scott, A. Bretscher, H. Ploegh, and P. Matsudaira, Molecular Cell Biology, W. H. Freeman and Company, New York, 6th edn, 2008.

3 E. Yashima, N. Ousaka, D. Taura, K. Shimomura, T. Ikai and K. Maeda, Chem. Rev., 2016, 116, 13752-13990.

4 X. de Hatten, D. Asil, R. H. Friend and J. R. Nitschke, J. Am. Chem. Soc., 2012, 134, 19170-19178.

5 H. Goto, H. Katagiri, Y. Furusho and E. Yashima, J. Am. Chem. Soc., 2006, 126, 7176-7178.

6 J. Shang, Q. Gan, S. J. Dawson, F. Rosu, H. Jiang, Y. Ferrand and I. Huc, Org. Lett., 2014, 16, 4992-4995.

7 H. Goto, Y. Furusho and E. Yashima, J. Am. Chem. Soc., 2007, 129, 9168-9174. 
8 T. Ben, Y. Furusho, H. Goto, K. Miwa and E. Yashima, Org. Biomol. Chem., 2009, 7, 2509-2512.

9 N. Saito, H. Kobayashi and M. Yamaguchi, Chem. Sci., 2016, 7, 3574-3580.

10 N. Saito, H. Kobayashi and M. Yamaguchi, Tetrahedron, 2017, 73, 6047-6051.

11 M. Shigeno, Y. Kushida and M. Yamaguchi, ChemPhysChem, 2015, 16, 2076-2083.

12 M. Shigeno, Y. Kushida and M. Yamaguchi, Chem. Commun., 2016, 52, 4955-4970.

13 N. Saito and M. Yamaguchi, Molecules, 2018, 23, 277-311.

14 T. Takamuku, A. Nakamizo, M. Tabata, K. Yoshida, T. Yamaguchi and T. Otomo, J. Mol. Liq., 2003, 103-104, 143-159.
15 J. N. Nayak, M. I. Aralaguppi, B. V. K. Naidu and T. M. Aminabhavi, J. Chem. Eng. Data, 2004, 49, 468-474.

16 M. Katayama and K. Ozutsumi, J. Solution Chem., 2008, 37, 841-856.

17 X. Feng, B. Tong, J. Shen, J. Shi, T. Han, L. Chen, J. Zhi, P. Lu, Y. Ma and Y. Dong, J. Phys. Chem., 2010, 114, 16731-16736.

18 Y. Marcus, J. Mol. Liq., 2012, 166, 62-66.

19 S. Indra, B. Guchhait and R. Biswas, J. Chem. Phys., 2016, 144, 124506.

20 E. Brini, C. J. Fennell, M. Fernandez-Serra, B. Hribar-Lee, M. Luksic and K. A. Dill, Chem. Rev., 2017, 117, 1238512414. Also see, E. E. Meyer, K. J. Rosenberg and J. Israelachvili, Proc. Natl. Acad. Sci., 2006, 103, 15739-15746. 